\title{
The US Food and Drug Administration's Proposed Rule to Increase Regulation of Indoor Tanning Devices
}

Elliot J. Coups, PhD Rutgers Cancer Institute of New Jersey, Rutgers, The State University of New Jersey, New Brunswick.

Alan C. Geller, MPH, RN Department of Social and Behavioral Sciences, Harvard School of Public Health, Boston, Massachusetts.

Sherry L. Pagoto, PhD Division of Preventive and Behavioral

Medicine, Department of Medicine, University of Massachusetts Medical School, Worcester.
Corresponding Author: Elliot J. Coups, PhD, Rutgers Cancer Institute of New Jersey, Rutgers, The State University of New Jersey, 195 Little Albany St, New Brunswick, NJ 08903 (elliot.coups @rutgers.edu).
Tanning bed use, particularly among teen girls and young adult women, has become a modern-day epidemic in the past 20 years. Numerous studies have established the link between indoor tanning use and skin cancer, including melanoma. Reducing the harms of indoor tanning is one of 5 goals outlined in the 2014 US Surgeon General's "Call to Action to Prevent Skin Cancer." Consistent with the Call to Action, on December 22, 2015, the US Food and Drug Administration (FDA) issued a proposed rule with the following restrictions for sunlamp products (ie, indoor tanning beds and booths): (1) to ban their use among individuals younger than 18 years; (2) to require prospective users to sign a risk acknowledgment certification; and (3) to provide user manuals to customers and tanning facility operators on request. ${ }^{2}$

The proposed rule to ban indoor tanning among minors younger than 18 years represents a landmark step in the regulation of sunlamp products in the United States. To date, restricting indoor tanning by age has been done on a state-by-state level. Successful statewide legislative efforts, leading to prohibition of indoor tanning for minors younger than 18 years in 13 states, undoubtedly led the FDA to propose a national ban among minors. Spurred by extensive public health advocacy coupled with data on the harms and growing use of tanning beds, youth access restrictions have spread quickly across the country in the past 4 years (the first ban for use by those $<18$ years went into effect in California in January 2012). It is noteworthy, and appropriate, that the proposed rule makes no provision for parental consent of indoor tanning among minors, which is included in current regulations for 17 states, but commonly flouted by indoor tanning salons. ${ }^{3}$ Parental consent provisions are also inconsistent with regulations for other healthdamaging products, such as laws that prohibit the sale of tobacco products to minors.

Prohibiting indoor tanning among individuals younger than 18 years is an important step in reducing teen use, which now exceeds $30 \%$ among non-Hispanic white girls ages 16 and 17 years ( $32 \%$ and $39 \%$ of whom, respectively, report indoor tanning at least once in the past year). ${ }^{4}$ Future research evaluating the impact of the ban on use by those younger than 18 years is needed, including ongoing surveillance of indoor tanning rates and practices among minors and adults, as well as epidemiologic and economic analyses of skin cancer morbidity and mortality. Research on the impact of the ban on age of indoor tanning initiation may be especially important given that a ban on use by those younger than 18 years does not entirely remove tanning from the high school years, a time when many individuals adopt the behavior. Given that most tanners initiate indoor tanning before the age of 21 years, ban on use by those younger than 21 years could have a more significant impact on indoor tanning-related skin cancer morbidity and mortality. To thwart the harms of indoor tanning, Brazil and Australia have prohibited indoor tanning for all individuals. Research is needed to establish the impact of different indoor tanning bans (eg, for those $<18$ years, < 21 years, all individuals) on skin cancer outcomes and health care costs.

The proposed rule requires prospective adult users to sign a 1-page risk acknowledgment certification form highlighting indoor tanning risks, contraindications, and precautionary measures prior to indoor tanning and every 6 months thereafter. We suggest that text be added to the certification to counter the false claims commonly touted by the industry regarding health benefits associated with indoor tanning (eg, reduced risk of certain cancers, optimal production of vitamin D). The certification includes language suggesting that people with a personal or family history of skin cancer should consult their physician. We suggest that this language be modified to more definitively state that such individuals should avoid using indoor tanning devices. Future research should also examine the optimal content and format of the certification and its impact on a range of outcomes among prospective and current indoor tanners, including emotional reactions, perceived risks of indoor tanning, attitudes, beliefs, intentions, and behaviors. Drawing on substantial evidence related to tobacco warnings, and nascent research on indoor tanning warnings, this research should focus on message framing and the use of text and graphic imagery.

The proposed restrictions are subject to 2 broad considerations. First, they pertain only to operators of indoor tanning facilities, defined as individuals who offer for sale the use of sunlamp products. Thus, it is unclear if they would apply to apartment buildings, fitness facilities, or other locations where indoor tanning is available at no direct expense to the user. A recent study revealed that $41 \%$ of indoor tanners reported having ever tanned in locations other than traditional indoor tanning salons. ${ }^{5}$ Tanning facility operators may also consider ways to circumvent any new regulations, for example by providing access to sunlamp products for free to minors who purchase other services (eg, spray tanning). We encourage the US Food and Drug Administration (FDA) and state agencies to apply the proposed rule across diverse commercial and residential 
(eg, apartment buildings) settings where sunlamp products are used. A further consideration of the proposed regulations is the potential unintended consequence of increasing tanning bed use in private homes, which would be unsupervised and unregulated. Research is needed to examine the impact of the proposed legislation on the locations where people use tanning beds.

Second, the impact of any resulting legislation will depend, in large part, on how well compliance with enforcement provisions is monitored and actually enforced. An analysis of the first 6 states to enact tanning bans for minors revealed considerable variability in their enforcement provisions. ${ }^{6}$ For example, all of the statutes stipulated penalties for violations, but only 3 states established tanning facility inspections and specified the department or agency responsible for enforcement. If the proposed rule is enacted, the FDA and relevant state and local agencies must coordinate enforcement provisions, compliance monitoring of tanning facility operators, and enforcement of violations. Comprehensive monitoring of compliance will likely require states to invest necessary resources to hire, train, and supervise tanning facility inspectors. Ongoing efforts will also be required to evaluate enforcement activities and outcomes.

In conclusion, we consider the proposed rule to be a timely and important next step in addressing the significant harms of indoor tanning in the United States. As outlined herein, however, several issues warrant attention to maximize the public health benefits of the rule, and research is needed to examine the impact of bans and to determine the optimal age group to target. Going forward, public health advocates and those working to protect youth and young adults from the damaging effects of tanning bed use can draw invaluable lessons from tobacco control campaigns. Legislative efforts and landmark regulations related to indoor tanning are important components of a larger comprehensive public health strategy that should also embrace price regulation, taxation, advertising restrictions, and the use of mass media. In addition, the same active and thriving coalitions that have spearheaded the most recent initiatives to restrict indoor tanning should expand and work in a sustained fashion toward dramatically reducing the estimated 419000 cases of skin cancer caused by indoor tanning each year in the United States. ${ }^{7}$

\section{ARTICLE INFORMATION}

Published Online: March 16, 2016. doi:10.1001/jamadermatol.2016.0504.

Conflict of Interest Disclosures: None reported.

\section{REFERENCES}

1. US Department of Health and Human Services. The Surgeon General's Call to Action to Prevent Skin Cancer. Washington, DC: US Dept of Health and Human Services, Office of the Surgeon General; 2014

2. Department of Health and Human Services, Food and Drug Administration. General and Plastic Surgery Devices: Restricted Sale, Distribution, and
Use of Sunlamp Products. Fed Regist. 2015;80 (245):79493-79505

3. Pagoto S, Hillhouse J, Heckman CJ, et al. Society of Behavioral Medicine (SBM) position statement: ban indoor tanning for minors. Trans/ Behav Med. 2014;4(1):124-126.

4. Guy GP Jr, Berkowitz Z, Everett Jones S, Holman DM, Garnett E, Watson M. Trends in indoor tanning among US high school students, 2009-2013. JAMA Dermatol. 2015;151(4):448-450.

5. Bulger AL, Mayer JE, Gershenwald JE, Guild SR Gottlieb MA, Geller AC. Enforcement provisions of indoor tanning bans for minors: an analysis of the first 6 US states. Am J Public Health. 2015;105(8): e10-e12.

6. Hillhouse J, Stapleton JL, Florence LC, Pagoto S Prevalence and correlates of indoor tanning in nonsalon locations among a national sample of young women. JAMA Dermatol. 2015;151(10): 1134-1136.

7. Wehner MR, Chren M-M, Nameth D, et al. International prevalence of indoor tanning: a systematic review and meta-analysis. JAMA Dermatol. 2014;150(4):390-400. 